\title{
Kovid-19 Pandemi Sürecinde Türkiye Yöresel Koyun Üretiminin Arttırılmasında İvesi Koyunlarından Yararlanma
}

\section{Kadir KIRK ${ }^{* 1}$ (D)}

\author{
${ }^{1}$ Yüzüncü Yıl Üniversitesi Ziraat Fakültesi Zootekni Bölümü, 65080, Kampüs/Tuşba-Van
}

Öz: Ceylanpınar Tarım İşletmesi koşullarında, 2-3-4-5-6-7> yaşlı 537 baş ìvesi koyun sürüsünün, kuzulama parametreleri incelenerek, yaş gruplarına göre, tek, ikiz, toplam ve genel kuzulayan koyun sayı ve oranlarının belirlenmesi amacıyla bu çalışma yapılmışır. Bu kapsamda yaş gruplarına göre en yüksek, en düşük ve genel ortalama değerler sırasıyla (baş; \%, baş); 2 (yaş) $122 \pm 1.38 ; 89.71-14 \pm 1.09 ; 10.29,136 \pm 1.24$, 4 (yaş) 75 $\pm 1.39 ; 78.13-21 \pm 1.13 ; 21.87,96 \pm 1.26$ ve $448 \pm 1.33$; 83.43$89 \pm 1.11 ; 16.57,537 \pm 1.22$ olarak bulunmuştur. Doğum tipi ve cinsiyetin, kuzu doğum canlı ağılığı üzerine etkilerinin dağılımları incelendiğinde, tek erkek ( $\mathrm{kg} / \mathrm{baş})$, tek dişi $(\mathrm{kg} / \mathrm{baş})$, toplam tek kuzu sayısı (baş) ve genel ortalama tek kuzu doğum canlı ağırlı̆ı $(\mathrm{kg} / \mathrm{baş})$ ile, ikiz erkek ( $\mathrm{kg} / \mathrm{baş)}$ ) ikiz dişi $(\mathrm{kg} / \mathrm{baş})$, toplam ikiz (baş) ve genel ortalama ikiz kuzu doğum canlı ağırlığı (kg/baş) ortalamaları, en yüksek, en düşük ve genel olarak sıralandığında; 5 (yaş) $5.3 \pm 1.28,4.9 \pm 1.22-61 \pm 1.41$, $5.1 \pm 1.25 ; 4.6 \pm 1.29,4.0 \pm 1.22-32 \pm 1.15,4.3 \pm 1.30,2$ (yaş) $4.2 \pm 1.19,3.8 \pm 1.17-122 \pm 1.38,4.0 \pm 1.18 ; 3.6 \pm 1.19,3.1 \pm 1.14-$ $28 \pm 1.09,3.4 \pm 1.17$ olarak belirlenmiştir. Kuzulayan ana yaşı ile kuzulama tipi, kuzu cinsiyeti ve doğum canlı ağırlıkları arasında istatistiki olarak önemli farklılıkların olduğu $(p \leq 0.05)$ belirlenmiştir. Bu bağlamda, kovid-19 pandemi sürecinde artan koyun eti talebi, İvesi gibi kısıtlı koyun yetiştiriciliği koşullarında karşılanarak, yöresel koyun varlığı arttırılabilir. Kuzulama parametreleri bakımından, yüksek damızlık değerli popülasyonların yerli ırkların ıslahında damızlık materyali olarak kullanılması durumunda, yöresel ve bölgesel koyun üretim etkinliğinin arttırılmasına olanak sağlanacaktır. Böylece kovid-19 gibi Türkiye yöresel koyun üretimini doğrudan etkileyen risk faktörleri azaltılmış olacaktır.

Anahtar Kelimeler: İvesi, doğum, canlı ağırlık

Covid-19 pandemic process in Turkey to benefit from the local sheep Awassi in increasing production of sheep

Abstract: In Ceylanpınar State Farm conditions, 2-3-4-5-6-7> 537 head of the Awassi sheep flock, by examining the lambing parameters, this study was carried out to determine the number and ratio of single, twin, total and general lambs according to age groups. In this context, the highest, lowest and general average values according to age groups are respectively (head;\%, head); 2 (age) 122 $\pm 1.38 ; 89.71$ $14 \pm 1.09 ; 10.29,136 \pm 1.24,4$ (age) $75 \pm 1.39 ; 78.13-21 \pm 1.13 ; 21.87,96 \pm 1.26$ and $448 \pm 1.33 ; 83.43-89 \pm 1.11 ; 16.57,537 \pm 1.22$. When the distribution of the effects of birth type, sex on lamb birth live weight is examined, single male ( $\mathrm{kg} / \mathrm{head})$, single female ( $\mathrm{kg} / \mathrm{head})$, total of single lamb (head) and overall average single lamb birth live weight ( $\mathrm{kg} / \mathrm{head}$ ) When ordering twin male ( $\mathrm{kg} / \mathrm{head})$, twin female ( $\mathrm{kg} / \mathrm{head})$, total twin (head), overall average twin lamb birth live weight( $\mathrm{kg} / \mathrm{head}$ ) maximum, minimum and general respectively; 5 (age) $5.3 \pm 1.28$, $4.9 \pm 1.22-61 \pm 1.41,5.1 \pm 1.25 ; 4.6 \pm 1.29,4.0 \pm 1.22-32 \pm 1.15,4.3 \pm 1.30,2$ (age) $4.2 \pm 1.19,3.8 \pm 1.17-122 \pm 1.38,4.0 \pm 1.18 ; 3.6 \pm 1.19,3.1 \pm 1.14$ - 28 $\pm 1.09,3.4 \pm 1.17$, determined. This result were statistically significant differences between lambing mother age and lambing type, lamb

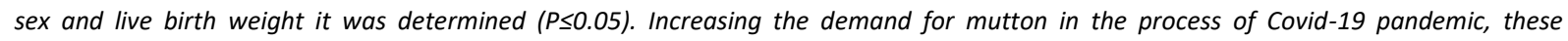
differences can be lamb meat under the conditions of limited sheep breeding, local sheep presence and sheep products can be increased. In terms of lambing parameters, if the high breeding populations are used as breeding material for the breeding of domestic breeds as Awassi, it will be possible to increase the local and regional sheep production efficiency. The pandemic negative impact of sheep breeding process can be minimized in Turkey.

Keywords: Awassi, birth, live weight

\section{GiRiş}

Koyun yetiştiriciliği, Türkiye kırsal alan nüfusunun, tarımsal üretim içindeki hayvansal üretim kaynağının önemli bir kısmını oluşturmaktadır. Yöresel koyun yetiştiriciliği ise, coğrafik ve ekolojik özellikler gereği sadece koyun yetiştirilebilen kırsal alan koşullarında, tarımsal üretim içindeki hayvansal üretimin $\% 81$ ve fazlasını oluşturmaktadır (Karaca ve ark., 1996; Gizaw ve ark., 2007; Kırk, 2011). Yerli koyun popülasyonlarında, ırklara ve bölgelere göre değişen döl verimi, popülasyonların süt, et gibi diğer verimlerinin de kaynağıdır. Tarih öncesinden günümüze insan yaşamında, vahşi yaşamda avlanarak edinilen hayvansal protein ihtiyacı, güncel teknolojik ve finansal olanaklar düzeyinde, yöresel satış alanları, bakkal, şarküteri, marketler, semt pazarları ve diğer alanlar ile mertopollerin hiper marketlerinden, insan tüketimine ulaşmaktadır. Yöresel koyun yetiştiriciliği ürünlerine ulaşım, üretim ve tüketim zinciri kapsamında diğer gıda maddeleri tedarik zincirlerine benzerdir. Ulusal ve uluslararası pandemi, doğal afet, sosyal veya ekonomik kriz dönemlerinde, mevcut koşullar gereği, genel gıda

Sorumlu Yazar: candemkkirk@gmail.com

Geliş Tarihi: 2 Haziran 2020

Kabul Tarihi: 30 Haziran 2020 
ürünlerine ulaşımda olduğu gibi, yöresel koyun ürünlerinin arz ve talep zincirinde de kopmalar ve aksamaların etkisiyle pandemi öncesi döneme ulaşım mümkün olmamaktadır. Global covid-19 pandemi sürecinde insanların, kısıtlı yaşam koşullarına adaptasyonu ve üretim sürecinde, arz kaynaklı, tüketim zincirinde ise ulaşım ve değişken fiyat kaynakı kısıtlar, yöresel koyun ürünlerinin üretim ve tüketiminde, ulusal ve uluslararası düzeyde sorunlar oluşturmuştur. Türkiye kırsal alan ekstansif koşullarında, yerli koyun ırklarının kuzulama etkinliği, \%62.1-74.6 arasındadır. Pandemi veya benzer faktörlerin olmadığı dönemlerde, uygulanan yetiştirme sistemi ve ıslah yöntemleri ile mevcut popülasyonların kuzulama etkinlikleri farklııılar gösterebilir (Tekin ve ark., 1991; Taşkın, 1995). Global covid-19 pandemi sürecinde, yöresel koyun eti ve koyun ürünlerine olan talebin karşılanabilmesi için damızlıkta kullanılacak erkek ve dişi materyalin talebe yönelik yüksek verim özellikli koyun ırkları ile üretim yapılarak, kuzulama verimliliği doğal koç katımı koşullarında \%92-95 düzeylerine çıkarılmalıdır. Dolayısıyla, mevcut yerli koyun ırklarının kuzulama etkinliklerinin ve yöresel koyun eti üretiminin arttırılması için, mevcut çevre koşullarına yüksek adaptasyonlu, yüksek döl, süt ve et verim yönlü İvesi koyun ırkı ıslah edici damızlık materyali olarak kullanılabilir (Sönmez, 1955; Pollott ve ark., 1998). Bu bağlamda, Türkiye mevcut yerli koyun ırklarında kuzulama etkinliğinin arttırılması acil eylem planı kapsamına alınarak, yöresel koyun eti üretiminde artış sağlanabilir. Ulusal ve uluslararası literatüre göre, mevcut koyun popülasyonlarının, verim özelliklerinin arttırıması yönündeki çalışmalar sıralandığında; Wilkes ve ark., (2017) Moğol yerli ırklarının melezleme ile ıslah çalışmalarında, saf Moğol ırkı sürüler ile Moğol-Barga ırkı popülasyonların çapraz melezlemesi yapılmışır. Melez döllerde canlı ağırlı̆ın arttığı, kötü iklim koşullarına adaptasyonun arttığı dolayısıyla sürü verimliliğin arttıılarak, popülasyonda kışbahar geçiş dönemlerindeki canlı ağılık kayıplarının azaldığını bildirmişlerdir $(p<0.05)$. Kırmızı et tüketimi içindeki \%46-48' lik koyun eti tüketiminin, global ve lokal risklerden olumsuz etkilenmemesi ve artan nüfusun koyun eti talebinin, dışa bağımlı kalmadan karşılanması gerekmektedir. Türkiye'de mevcut \%62.1-74.6 düzeyindeki kuzulama oranlarının \%83.3-92.7 düzeylerine çıkarılması için, acil koyun yetiştirme programları etkin hale getirilmelidir (Kaymakçı ve Sönmez., 1989; Kingwell ve ark.,1995; Kırk, 2019). Birçok ulusal ve uluslararası literatürde, koyun yetiştiriciliği ile kullanılan mera arazisi varlığının birlikte etkili olduğu bildirilmektedir, Morris (2009) Yeni Zellanda ve Avustralya koyun yetiştiriciliğinin ekonomisi üzerine yaptıkları çalışmada, dünya genelinde son beş yılda koyun sayısı ve koyun eti üretiminin hızla azaldığını, bu koşullarda dünya globalinde yüksek düzeyde artan koyun eti talebinin, Yeni Zellanda ve Avustralya'ı ihracatçılar tarafından karşılanamayacak düzeye ulaştı̆̆ını ancak, Yeni Zelanda koyun popülasyonlarında uygulanan lokal yetiştirme yöntemleri ile kuzulama verimlerinin 20 yılda \%98' den \%125'e, kuzu karkas ağırlıklarının ise 14-17 $\mathrm{kg} /$ baş'a çıkarıldığını bildirmişlerdir. Koyun üretimindeki bu ekonomik katma değerin, toplam tarımsal üretim içindeki sermaye getirisinin yılda \%1.0 düzeyine çıktığını ancak bitkisel üretimde kullanılmayan tarım arazilerinin, koyun yetiştiriciliğinde kullanılmaları ile koyun yetiştiriciliğinin ekonomik verimliliğinin $\% 10$ düzeyine ulaştığını tespit etmişlerdir. Ayrıca, sera gazı salınımının bitkisel üretime oluşturduğu negatif etkinin, koyun yetiştiriciliğinin ekonomik katma değer oluşumu ile dengelediğini bildirmiştir. Gizaw ve ark., (2007) köylerde Menz ırkı yöresel koyun ile çekirdek sürülerin canlı ağırlığa göre ıslah programlarında, sırası ile \%92.6-94.8 düzeyinde genetik ilerleme sağlandığı, bu ilerlemenin kalıtım derecesinin, 0.27 ile $0.86 \mathrm{~kg}$ arasında olduğunu, canlı ağırlık ve vücut ölçülerine göre uygulanan ıslah kriterleri arasındaki korelasyonun 0.40-0.98 önemli düzeyde isabetli olduğunu bildirmişlerdir. Kunene ve ark., (2009) farklı yaştaki Zulu koyunlarında, cinsiyetin, vücut ölçüleri, canlı ağırlık ve süt verim düzeyleri arasındaki ilişkilerin, damızlık değerleri üzerine etkilerini incelemişler. Buna göre damızlık değeri bakımından, vücut ölçüleri-canlı ağılık ile süt verimi arasındaki korelasyonun ( $r=0.21-0.48)$ düşük, canlı ağıllık korelasyonunun erkeklerde $(r=0.66-0.86)$ yüksek, dişilerde ise $(r=0.42-0.75)$ düşük $<15-22$ aylık genç erkeklerin canlı ağırlık korelasyonlarının $\left(R^{2}=0.61-0.80\right)$ yüksek, yaşlı koçlarda ise $\left(R^{2}=0.23-0.56\right)$ düşük düzeyde olduğunu bildirmişlerdir.

Zishiri ve ark., (2014) Güney Afrika koşullarında yetiştirilen, Dormer, lle de France ve Merino Landsheep ve terminal Sire koyun ırklarında doğum ve sütten kesim canlı ağırlıkları, maksimum olabilirlik (REML) prosedürlerini kullanarak, genetik parametre tahminleri yapmışlardır. Buna göre tek özellikli analizler kullanarak türettikleri doğrudan kalıtsallık tahminlerine (h2) göre, Dormer kuzularında, doğum, sütten kesim ve sütten kesim sonrası canlı ağılık kalıtım derecelerinin sırası ile, $0.25,0.28$ ve 0.37 'olduğunu, lle de France ve Merino Landsheep kuzularının, doğum, sütten kesim öncesi ve sütten kesim sonrası canlı ağırlık kalıtım derecelerinin ise sırası ile, $0.13,0.53,0.14$ ve $0.23,0.36$, 0.17 olduğunu belirlemişlerdir. Genetik, fenotipik ve çevresel korelasyonları, üç özellikli analiz kullanarak tahmin ettiklerinde, canlı ağılık korelasyonlarının Dormer kuzularında orta düzeyde, lle de France kuzularında ise yüksek düzeyde olduğunu, terminal Sire koyun ırklarında, canlı ağırlığa göre genetik parametre tahminleri ile damızlık seçiminde, isabet derecesinin yüksek olduğunu bildirmişlerdir. Wall ve ark., (2018) Yeni Zellanda koyun ırklarının \%70.0-95.0'nin 18-19 aylık yaşta aşımda 
kullanılabileceğini bildirmişlerdir. Yerli koyun ırklarının kuzulama etkinliğinin ve yöresel koyun ürünlerinin arttırıması için, İvesi gibi yüksek damızlık değerli koçların, etkin doğal aşım programlarında kullanılmaları veya pedigrili sürüler, yetiştirici koşullarında taze sperma ile yapay tohumlanmalıdır (Sönmez, 1955; Pollott ve ark., 1989).

Bu çalışmanın amacı; mevcut yerli koyun popülasyonlarının köylü koşullarındaki kuzulama etkinliğini, kontrollü doğal aşım veya saha koşullarında taze sperma ve yapay tohumlama teknikleri ile yaygın hale getirecek, acil hayvansal üretim programları uygulayarak, kovid-19 pandemik etkisine benzer, ulusal ve uluslararası risk dönemlerinde, yerli koyun popülasyonlarının yüksek verimli koyun sayısını ve birim koyundan elde edilecek et, süt, döl vb. verim özelliklerini arttırmaktır.

\section{MATERYAL VE YÖNTEM}

\section{Materyal}

Araştırma materyali olarak; Ceylanpınar Tarım İşletmesi koşullarında yetiştirilen, 2-3-4-5-6-7> yaşlı 537 baş, değişik yaşlı İvesi koyun sürüsünün kuzulama parametreleri kullanılmıştır. Kuzulama parametreleri olarak, 448 baş tek ve 178 baş ikiz doğan erkek ve dişi kuzu olmak üzere toplam 626 baş İvesi kuzunun doğum canlı ağırlık parametreleri olmak üzere genel toplam 1163 baş İvesi ana ve kuzusuna ilişkin kuzulama parametreleri kullanılmıştır.

\section{Yöntem}

Araştırma sürüsünün koç katımı, 1/35-45 baş erkek/dişi oranında elde aşım yöntemi ile yapılmıştır. Kuzulama dönemi parametreleri, pedigri kayıtlı olup, değişik yaşlı anaların doğum dönemi, kuzu doğum tipi ve kuzu cinsiyetlerine göre, kuzu doğum canlı ağırlık parametreleri belirlenmiştir. Kuzu doğum canlı ağırlıkları, doğumun ilk günü, $10 \mathrm{gr}$ hassasiyetli elektronik terazi ile kg olarak belirlenmiştir (Şekil 1, Şekil 2, Şekil 3 ve Şekil 4).

\section{İstatistiki Analiz}

Elde edilen verilerin istatistiki analizleri, SAS-GLM (2017) prosedürü ile yapılmıştır.

\section{BULGULAR VE TARTIŞMA}

Ceylanpınar Tarım İşletmesi yarı-entansif koşullarında yetiştirilen, 2-3-4-5-6-7> yaşlı, toplam 537 baş İvesi koyunun, kuzulama parametreleri ana yaş gruplarına göre, kuzu doğum tipi ve cinsiyetin, doğum canlı ağırlığı üzerine etkileri incelenmiştir. Çizelge 1'de kuzulama parametreleri görülmektedir.

Çizelge 1 ' incelendiğinde, tek kuzulama oranı \%89.71 ile en yüksek 2 yaş, en düşük \%78.13 ile 4 yaş grubunda, ortalama \%83.43 oranında, olduğu belirlenmiştir. Araştırma sürüsünde, ikiz kuzulayan koyunların yaş gruplarına göre dağılımları incelendiğinde, \%21.87 ile en yüksek ikizlik oranı 4 yaşlı kuzulayan koyun grubunda iken, en düşük ikizlik oranı, \%10.29 ile 2 yaş grubu kuzulayan koyunlarda olup, sürünün genel ikiz kuzulama oranının \%16.57 olduğu belirlenmiştir. İvesi koyunlarının tek ve ikiz kuzulama

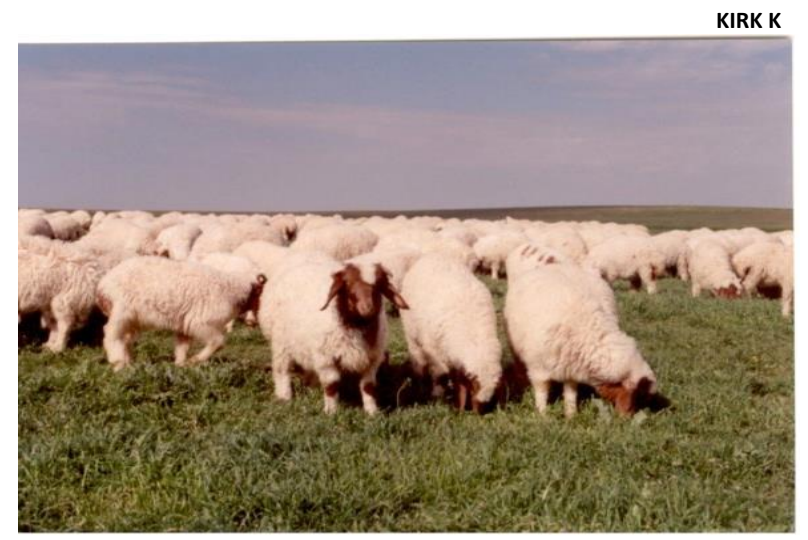

Şekil 1. İvesi kuzu sürüsü

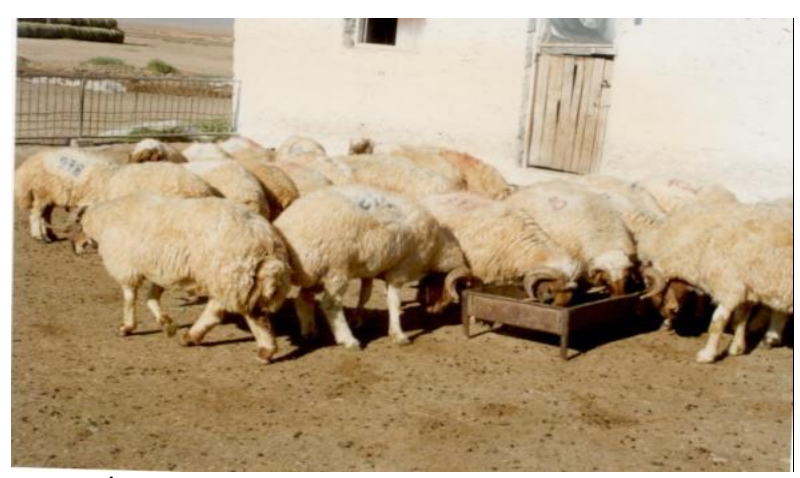

Şekil 2. İvesi toklu sürüsü

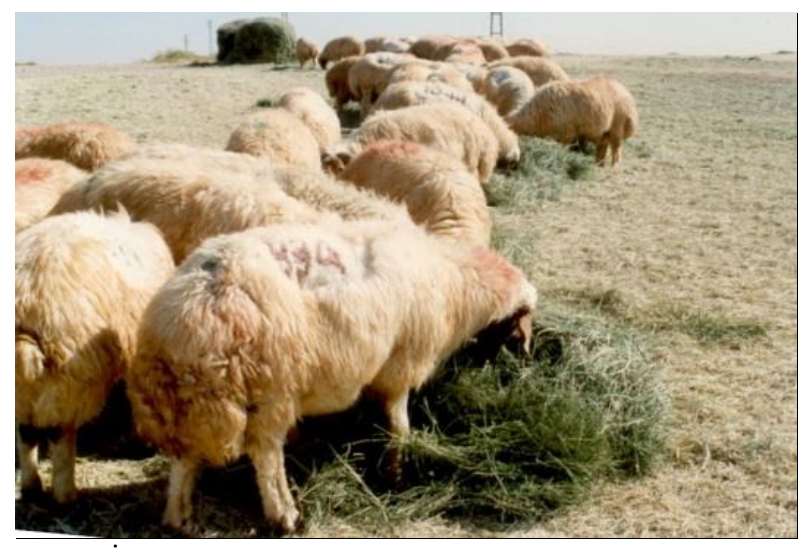

Şekil 3. İvesi koç sürüsü

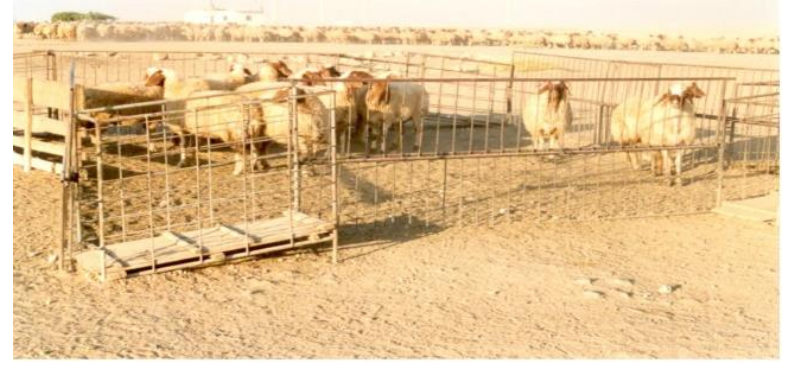

Şekil 4. İvesi koyun sürüsü 
Kovid-19 Pandemi Sürecinde Türkiye Yöresel Koyun Üretiminin Arttırılmasında

ivesi Koyunlarından Yararlanma

Çizelge 1. İvesi koyunlarında kuzulamanın yaş gruplarına göre dağılımı

\begin{tabular}{|c|c|c|c|c|c|c|c|}
\hline \multirow[t]{2}{*}{ Özellikler } & \multicolumn{6}{|c|}{ Kuzulayan koyun yaşı } & \multirow[t]{2}{*}{ Toplam } \\
\hline & 2 yaş & 3 yaş & 4 yaş & 5 yaş & 6 yaş & $7>$ yaş & \\
\hline Tek kuzulayan koyun (n) & $122 \pm 1.38$ & $96 \pm 1.31$ & $75 \pm 1.39$ & $61 \pm 1.41$ & $57 \pm 1.27$ & $37 \pm 1.21$ & $448 \pm 1.33$ \\
\hline Tek kuzulama oranı (\%) & 89.71 & 83.48 & 78.13 & 79.22 & 83.82 & 82.22 & 83.43 \\
\hline İkiz kuzulayan koyun (n) & $14 \pm 1.09$ & $19 \pm 1.11$ & $21 \pm 1.13$ & $16 \pm 1.15$ & $11 \pm 1.09$ & $8 \pm 1.06$ & $89 \pm 1.11$ \\
\hline İkiz kuzulama oranı (\%) & 10.29 & 16.52 & 21.87 & 20.78 & 16.18 & 17.78 & 16.57 \\
\hline Toplam kuzulayan koyun (n) & $136 \pm 1.24$ & $115 \pm 1.21$ & $96 \pm 1.26$ & $77 \pm 1.28$ & $68 \pm 1.18$ & $45 \pm 1.14$ & $537 \pm 1.22$ \\
\hline
\end{tabular}

${ }^{*} \mathrm{n}=$ baş, ${ }^{*}(\mathrm{P} \leq 0.05)$

oranlarının aynı sürü içinde birbiri içinde doğrusal ilişkili korelasyon gösterdiği, kuzulayan koyunlarda yaş ilerledikçe tek kuzulama oranının azalan hızla sürü ortalamasının altına gerilediği, ikiz kuzulama oranının ise kuzulayan ana yaş gruplarına göre azalan hızla artarak, sürü ikizlik oranının altına gerilediği görülmektedir. Araştırma sürüsündeki İvesi koyunlarının kuzulama oranlarına göre her iki sonuç birlikte değerlendirildiğinde, 7> yaş ve üzerinde koyunlarda kuzulama etkinliğinin verimliliği ve ekonomikliğinin azalacağı söylenebilir. Bu durum literatürdeki diğer yerli ve kültür ırkı koyun sürülerinin kuzulama verimliliği ile benzerlik gösterdiği söylenebilir (Berkyürek ve İzgür, 1992; Gizaw ve ark., 2007; Milan ve ark., 2011; Kırk, 2018). Kuzulayan ana yaş gruplarına göre, tek kuzulamanın, kuzu cinsiyetlerine göre dağılımları incelendiğinde (Çizelge 2); kuzulayan koyun yaş gruplarına göre tek kuzulamanın cinsiyete göre dağılımları, tek erkek kuzu sayı ve oranları ile, tek dişi kuzu sayı ve oranlarının dağılımı belirlenmiştir. Toplam tek doğan kuzuların kuzulayan ana yaş gruplarına göre dağııımları incelendiğinde sırası ile (baş); 2 (yaş) $122 \pm 1.38,3$ yaş $96 \pm 1.31,4$ (yaş) $75 \pm 1.39,5$ yaş $61 \pm 1.41,6$ yaş $57 \pm 1.27,7>$ (yaş) $37 \pm 1.21$ ve toplam $448 \pm 1.33$ olarak belirlenmiştir. İvesilerin kuzulama verimlerine ilişkin bu sonuçlar, ulusal ve uluslararası çalışmalara benzerlik göstermektedir (Sönmez, 1955; Gizaw ve ark., 2007; Milán ve ark., 2011).

Araştırmada, tek erkek kuzulama oranlarının \%47.54\%47.92 ile 2 ve 3 yaş grubu kuzulayan anaların kuzulamalarında belirlendiği, bu oranların, istatistiki olarak önemli düzeyde sürü ortalamasının altında olduğu, 4 yaş grubunun \%52.00 kuzulama oranının, 5-6 ve 7> üstü kuzulayan anaların kuzulama oranlarının ise sırası ile $\% 57.38$, \%54.39 ve \%54.05 istatistiki olarak, sürü tek kuzulama oranları ortalaması $\% 52.21$ 'in üstünde olduğu belirlenmiştir $(p \leq 0.05)$. Tek dişi kuzulama oranının ise, $2-3$ yaşlı kuzulayan analarda sırası ile $\% 52.46$ ve $\% 52.08$ olarak, tek erkek kuzulamanın tersine, ana yaşı ilerledikçe artarak, istatistiki olarak önemli düzeyde tek dişi kuzulama sürü ortalamasının \%48.88'in üstünde olduğu saptanmıştır $(p \leq 0.05)$. Kuzulayan ana yaş gruplarına göre tek erkek ve tek dişi kuzulamanın, ana yaşının etkisi ile, ana yaşı ilerledikçe tek erkek kuzulama oranının arttığı, tek dişi kuzulama oranının ise azaldığı tespit edilmiş olup, bu sonucun damızlık değeri yüksek popülasyonlar için önemli bir avantaj olduğu, yüksek süt ve et verim yönlü kombine büyüme ve gelişme potansiyelli yüksek yerli koyun ırkı i̇vesi popülasyonunun, Türkiye koyun varlığının arttırılmasında önemli bir hayvansal üretim kaynağı ve gen kaynağı olarak kullanılabileceğini göstermektedir. Diğer bir ifade ile, damızlık değeri yüksek ìvesi erkek materyallerin, damızlık olarak kullanılmaları durumunda, popülasyonlardaki yüksek verimli koyun sayısının ve birim koyun başına et, süt ve döl verim özelliklerinin kontrollü olarak arttırılmasına olanak sağlanabilir (Kaymakçı ve Sönmez 1989; Fisher, 2004; Kırk, 2010). Kuzulayan ana yaş gruplarına göre ikiz kuzulamanın kuzu cinsiyetlerine göre dağıımları (çizelge 3 ).

Çizelge 2. İvesi koyunlarında tek kuzulamanın doğuran koyun yaş gruplarına göre dağııımı

\begin{tabular}{llllllll}
\hline & \multicolumn{4}{c}{ Kuzulayan koyun yaş grupları } & \multicolumn{3}{c}{ Toplam } \\
\cline { 2 - 6 } & 2 yaş & 3 yaş & 4 yaş & 5 yaş & 6 yaş & $7>$ yaş \\
\hline Doğan tek kuzu (n) & $122 \pm 1.38$ & $96 \pm 1.31$ & $75 \pm 1.39$ & $61 \pm 1.41$ & $57 \pm 1.27$ & $37 \pm 1.21$ & $448 \pm 1.33$ \\
Tek erkek kuzu (n) & $58 \pm 1.42$ & $46 \pm 1.33$ & $39 \pm 1.32$ & $35 \pm 1.46$ & $31 \pm 1.23$ & $20 \pm 1.20$ & $229 \pm 1.36$ \\
Tek erkek kuzu oranı (\%) & 47.54 & 47.92 & 52.00 & 57.38 & 54.39 & 54.05 & 52.21 \\
Tek dişi kuzu(n) & $64 \pm 1.34$ & $50 \pm 1.29$ & $36 \pm 1.45$ & $26 \pm 1.36$ & $26 \pm 1.31$ & $17 \pm 1.22$ & $219 \pm 1.30$ \\
Tek dişi kuzu oranı (\%) & 52.46 & 52.08 & 48.00 & 42.62 & 45.61 & 45.95 & 48.88 \\
\hline
\end{tabular}

${ }^{*} \mathrm{n}=$ baş, ${ }^{*}(\mathrm{P} \leq 0.05)$

Çizelge 3. İvesi koyunlarında ikiz kuzulamanın doğuran koyun yaş gruplarına göre dağılımı

\begin{tabular}{llllllll} 
Özellikler & \multicolumn{5}{c}{ Kuzulayan koyun yaş grupları } & \multicolumn{1}{c}{ Toplam } \\
\cline { 2 - 6 } & 2 yaş & 3 yaş & 4 yaş & 5 yaş & 6 yaş & $7>$ yaş \\
\hline Doğan ikiz kuzu (n) & $28 \pm 1.09$ & $38 \pm 1.11$ & $42 \pm 1.13$ & $32 \pm 1.15$ & $22 \pm 1.09$ & $16 \pm 1.06$ & $178 \pm 1.11$ \\
İkiz erkek kuzu (n) & $13 \pm 1.14$ & $18 \pm 1.09$ & $22 \pm 1.13$ & $18 \pm 1.22$ & $12 \pm 1.06$ & $7 \pm 1.03$ & $90 \pm 1.12$ \\
İkiz erkek kuzu oranı (\%) & 46.43 & 47.37 & 52.38 & 56.25 & 54.55 & 43.75 & 50.02 \\
İkiz dişi kuzu (n) & $15 \pm 1.03$ & $20 \pm 1.14$ & $20 \pm 1.14$ & $14 \pm 1.08$ & $10 \pm 1.12$ & $9 \pm 1.09$ & $88 \pm 1.10$ \\
İkiz dişi kuzu oranı (\%) & 53.57 & 52.63 & 47.62 & 43.75 & 45.45 & 56.25 & 49.98 \\
\hline
\end{tabular}

${ }^{*} \mathrm{n}=$ baş, ${ }^{*}(\mathrm{P} \leq 0.05)$ 
Çizelge 3 incelendiğinde, ikiz kuzulayan İvesi koyun yaş gruplarına göre, kuzulamanın cinsiyete göre dağılımları, ikiz erkek kuzu sayı ve oranları ile ikiz dişi kuzu sayı ve oranları sırası ile (baş/\%); 2(yaş) 13 $\pm 1.14 ; 46.43-15 \pm 1.03 ; 53.57$,

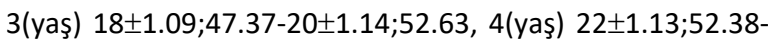
$20 \pm 1.14$ 47.62, 5(yaş) 18 $\pm 1.22 ; 56.25-14 \pm 1.08 ; 43.75,6$ (yaş) $12 \pm 1.06 ; 54.55-10 \pm 1.12 ; 45.45, \quad 7>$ (yaş) $7 \pm 1.03 ; 43.75-$ $9 \pm 1.09 ; 56.25$ ve toplam $90 \pm 1.12 ; 50.02-88 \pm 1.10 ; 49.98$ olarak belirlenmiştir. Toplam ikiz doğan kuzuların, kuzulayan ana yaş gruplarına göre dağılımları ise sırası

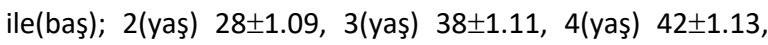
5 (yaş) $32 \pm 1.15,6$ (yaş) $22 \pm 1.09,7>$ (yaş) $16 \pm 1.06$ ve genel toplam ikiz kuzu 178 \pm 1.11 olarak belirlenmiştir (Berkyürek ve İzgür., 1992; Taşkın, 1995; Kırk, 2019). Aynı araştırmada, kuzulayan koyun yaş gruplarına göre doğan kuzuların, doğum canlı ağırlıklarının, kuzu doğum tipi ve kuzu cinsiyetlerine göre dağılımları Çizelge 4'te verilmiştir. Buna göre farklı yaşlı İvesi koyun sürüsünde, kuzulayan ana yaş gruplarına göre, doğum tipi ve kuzu cinsiyetinin doğum ağırlıkları üzerine etkilerinin dağılımları incelendiğinde; tek erkek ( $\mathrm{kg} / \mathrm{baş})$, tek dişi ( $\mathrm{kg} / \mathrm{baş}$ ) ve toplam tek kuzu sayıları (baş) ile ortalama canlı ağırlıkları (kg/baş) ile ikiz erkek (kg/baş), ikiz dişi ( $\mathrm{kg} / \mathrm{baş)} \mathrm{ve} \mathrm{toplam} \mathrm{ikiz} \mathrm{kuzu} \mathrm{sayıları} \mathrm{(baş)}$ ile ortalama canlı ağırlıkları ( $\mathrm{kg} / \mathrm{baş)} \mathrm{olarak} \mathrm{belirlenmiştir.}$ Buna göre ana yaş grublarına göre, kuzu doğum canlı ağırlık ortalamaları sırası ile, tek erkek, tek dişi, tek kuzu toplam ve genel ortalama doğum canlı ağırlıkları ile, ikiz erkek, ikiz dişi, toplam ve genel ikiz kuzu ortalama doğum canlı

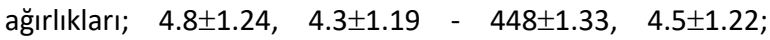
$4.0 \pm 1.23, \quad 3.6 \pm 1.19 \quad-\quad 178 \pm 1.11, \quad 3.8 \pm 1.22$ olarak belirlenmiştir. Ana yaş gruplarına göre, kuzu doğum ağırlıklarının doğum tipi ve kuzu cinsiyetine göre dağılımlarının analizlerinde, 2 yaş grubunda kuzulayan anaların tek dişi kuzularında en düşük ortalama $3.8 \pm 1.17$ (kg/baş), 5 yaş grubunda kuzulayan anaların tek erkek kuzularının ortalama $5.3 \pm 1.28$ ( kg/baş) ile en yüksek kuzu doğum canlı ağırlığına sahip oldukları, ikiz kuzulamalarda ise en düşük ortalama doğum canlı ağırlığının 2 yaş grubunda kuzulayan anaların ikiz dişi kuzularının ortalama doğum canlı ağırlığı $3.1 \pm 1.14$ (kg/baş) olduğu, en yüksek ortalama doğum canlı ağırlığı ise 5 yaş grubunda kuzulayan anaların ikiz erkek kuzularının ortalama doğum canlı ağırlığının $4.6 \pm 1.29$ (kg/baş) olduğu belirlenmiştir. Buna göre, kuzulayan ana yaş grubu, kuzu doğum tipi ve cinsiyetinin, ortalama kuzu doğum canlı ağırıklarının belirlenmesinde istatistiki olarak önemli düzeyde etkili olduğu, ana yaş grupları, doğum tipi ve kuzu cinsiyetleri bakımından, kuzulayan ana yaş grupları arasında ve aynı gruptaki kuzuların doğum tipi ve kuzu cinsiyetleri bakımından, ortalama kuzu doğum ağırlıkları arasında istatistiki olarak önemli düzeyde farklılıklar olduğu belirlenmiştir ( $p \leq 0.05$ ). Araştırma genelinde, tüm yaş grubunda kuzulayan anaların; tek erkek ve dişi kuzular ile genel ortalama tek kuzuların ortalama doğum canlı ağırlıkları sırası ile; $4.8 \pm 1.24$ ve $4.3 \pm 1.19$ ile $4.5 \pm 1.22(\mathrm{~kg} / \mathrm{baş})$ olarak belirlenirken, ikiz erkek ve dişi kuzular ile genel ortalama ikiz kuzuların ortalama doğum canlı ağırlıkları sırası ile; $4.0 \pm 1.23$ ve $3.6 \pm 1.19$ ile $3.8 \pm 1.22$ (kg/baş) olarak belirlemiştir. Kuzu doğum ağırlıkları bakımından bireyler arasındaki farklılıklar, aynı cinsiyetteki bireyler arasında bir yaşına kadar istatistiki olarak önemli etkiye sahip olup, bu durum bir çok yerli ve kültür ırkı koyun popülasyonunda tespit edilmiştir (Karaca ve ark., 1996; Kunene ve ark., 2009; Zishiri ve ark., 2014; Wilkes ve ark., 2017). Gizaw ve ark. (2008) tarafından Köylerde Menz ırkı yöresel koyun ve sürüleri ile çekirdek sürülerinin canlı ağırlığa göre ıslah programlarında, çekirdek sürülerine uygulanan seleksiyon programlarında, sırası ile \%92.6-94.8 düzeyinde genetik ilerleme sağlandığı, bu ilerlemenin kalıtım derecesinin ise, 0.27 ile 0.86 kg olduğu, canlı ağırlık ve vücut ölçülerine göre uygulanan ıslah kriterleri arasındaki korelasyonun 0.40-0.98 olarak önemli düzeyde isabetli olduğu bildirilmiştir. Kunene ve ark., (2009) her yaş grubundaki, farklı cinsiyetteki Zulu koyunlarının çeşitli vücut ölçüleri, canlı ağırlık ve süt verim miktarları arasındaki ilişkilerin, damızlık değerleri üzerine etkilerini inceledikleri araştırmalarında; vücut ölçüleri-canlı ağırlık ile süt verimi arasındaki ilişkilerin, damızlık değerleri bakımından korelasyonlarının $r=0.21-0.48$ düşük düzeyde olduğunu, canlı ağırlık bakımından erkekler arasında ( $r=0.66-0.86$ ) yüksek düzeyde korelasyon olduğu, damızlık değeri belirlemede, dişilere ait parametrelerin cinsiyet bakımından ( $r=0.42-0.75$ ) aralığında korelasyon olduğunu, $<15-22$ aylık genç erkeklerin canlı ağırlıkları ile damızlık değerinin $\left(R^{2}=0.61-0.80\right)$ aralığında yüksek düzeyde olduğunu, yaşlı koçların damızlık değeri-canlı ağırlık ilişkisi bakımından korelasyonunun $\left(R^{2}=0.23-0.56\right)$ düşük düzeyde olduğunu bildirmişlerdir.

Çizelge 4. İvesi kuzularında canlı ağırlığın kuzulayan ana yaş gruplarına göre dağılımı

\begin{tabular}{|c|c|c|c|c|c|c|c|}
\hline \multirow[t]{2}{*}{ Özellikler } & \multicolumn{6}{|c|}{ Kuzulayan koyun yaş grupları } & \multirow[t]{2}{*}{ Genel } \\
\hline & 2 yaş & 3 yaş & 4 yaş & 5 yaş & 6 yaş & $7>$ yaş & \\
\hline Tek erkek DCA(kg/baş) & $4.2 \pm 1.19$ & $4.6 \pm 1.21$ & $5.1 \pm 1.34$ & $5.3 \pm 1.28$ & $4.8 \pm 1.21$ & $4.6 \pm 1.18$ & $4.8 \pm 1.24$ \\
\hline Tek dişi DCA (kg/baş) & $3.8 \pm 1.17$ & $4.0 \pm 1.22$ & $4.7 \pm 1.26$ & $4.9 \pm 1.22$ & $4.2 \pm 1.16$ & $4.1 \pm 1.13$ & $4.3 \pm 1.19$ \\
\hline Tek kuzu (n) & $122 \pm 1.38$ & $96 \pm 1.31$ & $75 \pm 1.39$ & $61 \pm 1.41$ & $57 \pm 1.27$ & $37 \pm 1.21$ & $448 \pm 1.33$ \\
\hline Tek kuzu ort. DCA (kg/baş) & $4.0 \pm 1.18$ & $4.3 \pm 1.22$ & $4.9 \pm 1.30$ & $5.1 \pm 1.25$ & $4.5 \pm 1.19$ & $4.4 \pm 1.16$ & $4.5 \pm 1.22$ \\
\hline İkiz erkek DCA (kg/baş) & $3.6 \pm 1.19$ & $3.9 \pm 1.23$ & $4.1 \pm 1.27$ & $4.6 \pm 1.29$ & $4.1 \pm 1.24$ & $3.7 \pm 1.18$ & $4.0 \pm 1.23$ \\
\hline İkiz dişi DCA (kg/baş) & $3.1 \pm 1.14$ & $3.3 \pm 1.17$ & $3.8 \pm 1.21$ & $4.0 \pm 1.22$ & $4.0 \pm 1.18$ & $3.3 \pm 1.23$ & $3.6 \pm 1.19$ \\
\hline İkiz kuzu (n) & $28 \pm 1.09$ & $38 \pm 1.11$ & $42 \pm 1.13$ & $32 \pm 1.15$ & $22 \pm 1.09$ & $16 \pm 1.06$ & $178 \pm 1.11$ \\
\hline İkiz kuzu ort. DCA (kg/baş) & $3.4 \pm 1.17$ & $3.6 \pm 1.20$ & $4.1 \pm 1.24$ & $4.3 \pm 1.30$ & $4.1 \pm 1.21$ & $3.7 \pm 1.21$ & $3.8 \pm 1.22$ \\
\hline
\end{tabular}

${ }^{*} \mathrm{n}=$ baş, DCA=Doğum canlı ağırlığı * $(\mathrm{P} \leq 0.05)$ 
Yerli koyun popülasyonları içinde, yüksek döl, süt ve et verim yönlü İvesi koyun popülasyonları ulusal ve uluslararası literatürde, ıslah edici ırk olarak yaygın şekilde kullanılabilmektedir. Yerli koyun ırkların ıslahında İvesi'lerin etkin olarak kullanılabilmeleri durumunda, ıslah edilen popülasyonların, yüksek verimli koyun sayıları arttırılırken, birim koyun başına, döl, süt ve canlı ağırlıkları da arttırılabilecektir. Bu araştırma ile, kovid-19 pandemi sürecinin global olumsuz etkisi altında, kısıtlı tarımsal faaliyet içinde, kısıtlı hayvansal üretim seviyesine çekilen ülkemiz ve diğer ülkelerin bu gibi zamanlarında, mevcut yerli koyun ırklarının verim özelliklerinin iyileştirilmesi ve yüksek verim yönlü yerli koyun ırkı popülasyonlarının nitel ve nicel olarak arttırılmasına olanak sağlanacaktır. Çünkü pandemi süreçlerinde, ülkelerin dışa bağımlı kalmadan, kendi koşullarında ülke nüfuslarının bitkisel ve hayvansal üretimlerini karşılayabilecek düzeylere gelmeleri, her tarım sektöründe olduğu gibi, Türkiye koyun yetiştiriciliğinde de, hayvansal üretim stratejisi olmalıdır. Diğer bir ifadeyle insanların ve insanlığın geleceğe yönelik hedefleri, beslenmelerinde kullanacakları bitkisel ve hayvansal proteinlerin nitelik ve niceliği ile doğru ilişkilidir (Kırk, 2019).

\section{SONUÇ}

Türkiye kırsal alan yerli koyun popülasyonlarının kuzulama etkinliklerinin düşüklüğü birçok bilimsel kaynakta yer edinmiştir. Durum böyle iken, mevcut koyun popülasyonlarının, mevcut koşullardaki, kuzulama veriminin arttırıması acil tarımsal kalkınma programlarına alınmalı ki, koyun eti ve diğer ürünlerde dışa bağımlılık, ülke düzeyinde azalsın. Ancak yüzyılın global salgın felaketi olarak 11 Mart 2020 tarihinden itibaren, yöresel koyun yetiştiriciliği de kovid-19 pandemi sürecinin etkisi altında kalmıştır. Bu süreçte yöresel koyun sayısının ve birim koyun başına et, süt, döl verimi etkinliğinin arttırılması, koyun veya koyun ürünleri ithalatı ile sağlanamaz. Çünkü, bu süreçte, karantina tedbirleri kapsamında bulaş riski ile birlikte, ülke çapında cari açığın artmasına neden olabilir. Kovid-19 pandemi sürecinin acımasız etkisi ile düzeyini bilemediğimiz can kayıplarımızın bitmesi için, dünyanın birçok ülkesinde olduğu gibi, ülkemiz genelinde de, kısıtlı veya yarı kısıtlı yaşam tedbirleri uygulanmak zorunda kalınmıştır. Bu araştırmadaki kuzulama parametreleri ile literatür bildirişleri yorumlandığında, 4 yaş grubu ívesi anaların tek kuzulama oranlarının, tek kuzulama genel ortalamasından düşük düzeyde olması, ırk özelliklerinden kaynaklanabilir. $\mathrm{Bu}$ araştırmadan elde edilen, kuzulama verileri dikkate alındığında, Türkiye yerli koyun popülasyonlarında, yöresel koyun sürülerinin kuzulama etkinliğini arttırmak ve birim koyun başına, elde edilecek koyun eti üretimini etkin bir düzeyde arttırabilmek için, Ceylanpınar Tarım İşletmesinde bulunan, erkek toklu ve genç koçların, ülke genelindeki yöresel koyun popülasyonlarında, doğal koç katımı yöntemi ile veya taze sperma ile yapay tohumlama yöntemleri ile damızlıkta kullanılmaları gerekir. Böylece yöresel koyun popülasyonlarındaki yetiştirici koşullarında tek kuzulama oranlarının, \%78.13-83.43, ikiz kuzulama oranlarının ise \%16.57-21.87 düzeylerine çıkarılabileceği söylenebilir.
Bununla birlikte, elde edilecek tek kuzuların, erkek, dişi ve genel tek kuzu ortalama canlı ağırıkları sırası ile, 4.8 \pm 1.24 ve $4.3 \pm 1.19$ ile $4.5 \pm 1.22$ ( $\mathrm{kg} /$ baş) düzeylerine, ikiz kuzuların, erkek, dişi ve genel ikiz kuzu ortalama canlı ağırlıkları ise sırası ile, $4.0 \pm 1.23$ ve $3.6 \pm 1.19$ ile $3.8 \pm 1.22$ ( $\mathrm{kg} / \mathrm{baş}$ ) düzeylerine çıkarılabilecektir. Böylece, Türkiye koyun yetiştiriciliğini, riske edebilecek kovid-19 pandemi sürecinde ki riskler ve başka risklerin olumsuz etkileri minimize edilerek, yöresel koyun varlığı ve koyunlardan elde edilecek et, süt ve döl verimleri etkin bir şekilde arttırılabilecektir.

\section{KAYNAKLAR}

Berkyürek T, İzgür ì (1992) Koyunlarda Kuzulamanın Kontrolü, Doğa, Tr.J. of Veterinary and Animal Sciences, 16:353-361.

Fisher MW (2004) A review of the welfare implications of out-of-season extensive lamb production systems in New Zealand. Livestock Production Science, 85 (2-3): 165-172.

Gizaw S, Komen H, Van Arendonk JAM (2007) Selection on linear size traits to improve liwe weight in Menz sheep under nucleus and village breeding programs. Livestock production volume 118, Issues 1-2, October 2008, Pages 92-98.

Gizaw S, Lemma S, Komen H, Van Arendonk JAM (2008) Estimates of genetic parameteres and genetic trends for live weight and fleece in Menz sheep. Small Ruminant Research volume 70, Issues 2-3 July 2007 Pages 145-153.

Karaca O, Altın T, Okut H (1996) Köylü İşletmelerinde Karakaş Koyunları Canlı Ağırlık Değişimlerine iliş̧in Kimi Parametre Tahminleri. Yüzüncü Yıl Üniversitesi Ziraat Fakültesi Dergisi, Cilt 3 /1-2, Sayfa 33-40 Van.

Kaymakçı M, Sönmez R (1989) Türkiye'de Koyunlarda Verimliliği Arttırmanın Başlıca Yolları, Hayvansal Üretim Dergisi. 32: 1-13.

Kırk K (2010) Yapay Tohumlama Yöntemi ile Küçükbaş Hayvanlarda Genetik Üstünlüğün Korunması. Bilimde Modern Yöntemler Sempozyumu(BMYS 2010) 14-16 Ekim 2010 Dicle Üniversitesi - Diyarbakır.

Kırk K (2011) Yerli Koyun Irklarının Döl Verim Özelliklerinin İyileştirilmesinde Yapay Tohumlamadan Yararlanma Olanakları. VII. Ulusal Zootekni Bilim Kongresi. 14-16 Eylül 2011. Çukurova Üniversitesi Ziraat Fakültesi Balcalı-Adana.

Kırk K (2018) Breeding local dairy sheep production on Van province. Zootekni Federasyonu, 10th International Animal Science Conference Book. p. 159. 25-27 October, Antalya/Turkey.

Kırk K (2019) Taze ve Sulandırılmamış Sperma ile Yapay Tohumlanan Yerli Koyunların Döl Verim Özellikleri. Adnan Menderes Üniversitesi Ziraat Fakültesi Dergisi (Journal of Adnan Menderes University Agricultural Faculty), Cilt(Volume): 16(1):85-89.

Kingwell RS, Abadi Ghadim AK, Robinson SD, Young JM (1995) Introducing Awassi Sheep to Australia: an 
Application of Farming System Models. Agricultural Systems 47 (45): 1471.

Kunene NW, Nesamvuni AE, Nsahlai IV (2009) Determination of prediction equations for estimating body weight of Zulu (Nguni) sheep. Small Ruminant Research volume 84, Issues 1-3 June 2009 Pages 4146.

Milán MJ, Caja G, González-González R, Fernández-Pérez A $M$, Such X (2011) Structure and performance of Awassi and Assaf dairy sheep farms in northwestern Spain. J. Dairy Sci. 94:771-784.

Morris ST (2009) Economics of sheep production. Small Ruminant Research Volume 86, Issues 1-3, October 2009, Pages 59-62.

Pollott GE, Gürsoy O, Kırk K (1998) Genetics of milk and meat production in Turkish Awassi sheep. 6th World Congress on Genetics Applied to Livestock Production, 12-16 Jan 1998. Armidale- Australia. 24: 177-180.

Taşkın T (1995) Kıvırcık ve Dağlıç Erkek Kuzularında Kimi Üreme Özelliklerinin Mevsimsel Değişimi. Ege Üniv. Fen Bil. Enst. Zootekni Anabilim Dalı. 10.3100.0000.125 (Doktora Tezi), Bornova-Izmir.

Tekin N, Günzel-Apel AR, Yurdaydın N, Yavaş Y, Daşkın A, Keskin O, Etem H (1991) Oestruslerı Sinkronize Edilen
Koyunlarda, Sun'i Tohumlama Yöntemi ile Elde Edilen Döl Verimi. Ankara Üniversitesi Veteriner Fakültesi Dergisi. 38(1-2):60-73, (Ayrıbasım), Ankara.

SAS (2017) Statistical Analysis System. SAS Institute Inc., Cary, N.C.USA.

Sönmez R (1955) İvesi Koyunları Vücut Yapılışları, Çeşitli Verimleri ve Bunların Diğer Yerli Koyunlarla Çeşitli Verimler Bakımından Mukayeseleri. A.Ü. Zir. Fak. Yayınları, 74. Ankara.

Zishiri OT, Cloete SWP, Olivier JJ, Dzama K (2014) Genetic parameters for live weight traits in South African terminal sire sheep breeds. Small Ruminant Research Volume 116, Issues 2-3 February 2014 Pages 118-125.

Wall AJ, Juengel JL, Edwards S.J, Rendel J.M (2018) The economic value of replacement breeding ewes attaining puberty within their first year of life on New Zealand sheep farms Agricultural Systems. Volume 164, July 2018, Pages 38-46.

Wilkes A, Barnes P A, BaivalBatkhishig, Clare A, Namkhainyam B, Serenbandi T, Chuluunbaatar N, Namkhainyam T (2017) Is cross-breeding with indigenous sheep breeds an option for climate-smart agriculture. Small Ruminant Research Volume 147, February 2017 Pages 83-88. 
